\title{
Analysis of Sequenced Genomes of Xanthomonas perforans Identifies Candidate Targets for Resistance Breeding in Tomato
}

\author{
Sujan Timilsina, Peter Abrahamian, Neha Potnis, Gerald V. Minsavage, Frank F. White, Brian J. Staskawicz, \\ Jeffrey B. Jones, Gary E. Vallad, and Erica M. Goss
}

First, fourth, fifth, seventh, and ninth authors: Department of Plant Pathology, University of Florida, Gainesville; first, second and eighth authors: Gulf Coast Research and Education Center, University of Florida, Wimauma; third author: U.S. Vegetable Laboratory, 2700 Savannah Highway, USDA, Charleston, SC; sixth author: Department of Plant and Microbial Biology, University of California, Berkeley; and ninth author: Emerging Pathogens Institute, University of Florida, Gainesville.

Accepted for publication 5 July 2016.

\begin{abstract}
Timilsina, S., Abrahamian, P., Potnis, N., Minsavage, G. V., White, F. F., Staskawicz, B. J., Jones, J. B., Vallad, G. E., and Goss, E. M. 2016. Analysis of sequenced genomes of Xanthomonas perforans identifies candidate targets for resistance breeding in tomato. Phytopathology 106:1097-1104.

Bacterial disease management is a challenge for modern agriculture due to rapid changes in pathogen populations. Genome sequences for hosts and pathogens provide detailed information that facilitates effectorbased breeding strategies. Tomato genotypes have gene-for-gene resistance to the bacterial spot pathogen Xanthomonas perforans. The bacterial spot populations in Florida shifted from tomato race 3 to 4 , such

profiles among race 4 strains collected in 2006 and 2012 and compared with a race 3 strain collected in 1991. We examined variation in putative targets of resistance among Florida strains of $X$. perforans collected from 1991 to 2006. Consistent with race change, $a v r X v 3$ was present in race 3 strains but nonfunctional in race 4 strains due to multiple independent mutations. Effectors xopJ4 and $a v r B s 2$ were unchanged in all strains. The effector $a v r B s T$ was absent in race 3 strains collected in the $1990 \mathrm{~s}$ but present in race 3 strains collected in 2006 and nearly all race 4 strains. These changes in effector profiles suggest that xopJ4 and avrBsT are currently the best targets for resistance breeding against bacterial spot in tomato.
\end{abstract} that the corresponding tomato resistance gene no longer recognizes the effector protein AvrXv3. Genome sequencing showed variation in effector

Bacterial spot of tomato and pepper is caused by four distinct species within the genus Xanthomonas: $X$. vesicatoria, $X$. euvesicatoria, $X$. perforans, and X. gardneri (Jones et al. 2004). The disease is found in all areas in which tomato and pepper are grown and is most severe in areas with tropical and subtropical climates, including the southeastern United States. High temperatures, humidity, and rainfall favor disease development. The disease can cause yield losses of up to $50 \%$ in tomato (Scott et al. 1989). Current disease management strategies include resistant cultivars, use of diseasefree seeds and transplants, and the preventative application of antibiotics, copper-based bactericides, and the plant defense elicitor acibenzolar-S-methyl (Huang et al. 2012). Disease management has been challenged by changes in the pathogen population, including increased resistance to bactericides and shifts to different Xanthomonas races and species.

Four tomato races have been described based on the presence of specific effector genes that interact with the corresponding resistance genes in tomato cultivars (Stall et al. 2009). Strains that elicit a hypersensitive response (HR) only in the tomato differential genotype Hawaii 7998, which contains the three recessive resistant genes

Corresponding author: E. M. Goss; E-mail address: emgoss@ufl.edu

Nucleotide sequence data is available in the NCBI database under accession numbers KU759430 to KU759471 for partial gene sequences of gapA, KU759370 to KU759372 for complete coding regions of avrBsT, KU759373 to KU759401 for partial sequence of $a v r X v 3$, KU759402 to KU759429 for partial sequence of xopJ4, and KU759472 to KU759498 for partial sequence of xopQ.

*The $e$-Xtra logo stands for "electronic extra" and indicates that four supplementary figures and one supplementary table are published online.

Modified: 19 Sep 2019.

http://dx.doi.org/10.1094/PHYTO-03-16-0119-FI

(C) 2016 The American Phytopathological Society
Additional keywords: type III effectors, avirulence, recombination. $\mathrm{rx} 1, \mathrm{rx} 2$, and $\mathrm{rx} 3$ are designated as tomato race 1 (T1). Strains that produce a susceptible reaction in all of the tomato differentials are designated race 2 (T2). All T1 strains to date have been $X$. euvesicatoria (Stall et al. 2009). Initially, all T2 strains were $X$. vesicatoria (Stall et al. 2009); however, X. gardneri strains were determined to also behave as race 2 (J. B. Jones, unpublished data). A third pathogenic race, identified in the early 1990s, was designated as race 3 (T3). These strains were placed in a new species, $X$. perforans, which is closely related to but distinct from $X$. euvesicatoria. X. perforans T3 strains cause disease on Hawaii 7998 , like T2 strains, but carry the $a v r X v 3$ effector gene that elicits an incompatible reaction on tomato genotypes with the corresponding $X v 3$ resistance gene. Later, T3 strains were determined to contain another avirulence gene, $x o p J 4(a v r X v 4)$, which elicits a HR in Solanum pennellii LA 716 and other tomato genotypes with the RxopJ4 ( $X v 4$ ) resistant locus (Astua-Monge et al. 2000; Sharlach et al. 2013; Stall et al. 2009). X. perforans strains with xopJ4 but lacking a functional $a v r X v 3$ were later identified and designated as race 4 (T4). Surveys conducted in Florida in 2006 and 2012 showed a shift from T3 to T4, with $75 \%$ of the collected strains identified as T4 in 2006 (Horvath et al. 2012) and 100\% T4 by 2012 (Timilsina et al. 2015).

Most Xanthomonas species use the type III secretion system to transfer pathogen effectors into their hosts. The acquisition or mutation of various effectors governs Xanthomonas host range and virulence (Mhedbi-Hajri et al. 2013). Approximately 45 type III effector groups are associated with Xanthomonas spp. (Potnis et al. 2015; White et al. 2009). Type III effectors are known or hypothesized to facilitate disease. Effectors that are perceived by host resistance proteins ( $R$ genes) induce a HR (Nimchuk et al. 2003) that confers race-specific resistance (Stall et al. 2009). 
The durability of plant resistance, regardless of how it was introduced, depends on the ability of the pathogen to evolve over time. For bacterial pathogens, durability depends on rates of mutation, the ability to horizontally exchange genetic material, the overall level of selection pressure, and the relative fitness of virulent strains (Stall et al. 2009). Effectors that are conserved in pathogen populations can be evaluated as potential targets for resistance breeding. Resistance breeding strategies that target evolutionarily conserved effectors coupled with the pyramiding of $R$ genes could lead to durable resistance against pathogen populations.

The $B s 2$ resistance gene recognizes the core effector AvrBs2, which is present in all four Xanthomonas species that cause bacterial spot of tomato (Horvath et al. 2012; Potnis et al. 2011). However, this pepper gene is not available in commercial tomato cultivars. A transgenic approach was used to develop resistant tomatoes expressing the $B s 2$ transgene (Tai et al. 1999). The effectiveness of $B s 2$ in commercial peppers can be greatly diminished by the appearance of mutations within $a v r B s 2$ in $X$. euvesicatoria populations (Gassmann et al. 2000; Swords et al. 1996). In order to improve the durability of $B s 2$ resistance in tomato, additional effectors should be targeted for pyramiding of resistance genes, line mixing, or alternating resistance lines (McDonald and Linde 2002). Resistance targeting effector AvrBsT, which is present in some strains of $X$. euvesicatoria and $X$. vesicatoria, has been reported in Solanum lycopersicoides, but the resistance gene has not been identified and introgressed into tomato (Wang 1992). Likewise, resistance against the XopJ4 effector in $X$. perforans has been mapped to a 4.2-Mb cluster in S. pennellii (Sharlach et al. 2013). AvrBsT and XopJ4 are not considered core effectors because they are not present in all four bacterial spot species (Potnis et al. 2011). However, because resistance against these effectors is known, they are potential targets.

Whole genome sequence analyses of field strains of the four bacterial spot species revealed a high degree of variation in type III effectors within species (Schwartz et al. 2015). Even among the 11 core effectors, allelic variation was observed in XopAD, XopD, and XopQ in T4 $X$. perforans strains from Florida. Previously, multilocus analysis revealed recombination between strains of $X$. perforans and $X$. euvesicatoria that generated two different genetic groups of T4 $X$. perforans strains in Florida (Timilsina et al. 2015). Strains designated as group 1 were similar to the taxonomic type strain for $X$. perforans, strain 91-118, a T3 strain collected in Florida in 1991, while group 2 strains had sequence similarities with $X$. euvesicatoria (Timilsina et al. 2015). This pattern was also observed for the type III effector $x o p Q$, such that $X$. perforans strains with the $X$. euvesicatoria gapA sequence also had the $X$. euvesicatoria $x o p Q$ sequence (Schwartz et al. 2015; Timilsina et al. 2015). The specific molecular function of XopQ in pathogenicity is unknown (Teper et al. 2014). Subsequent wholegenome comparisons of T4 strains identified two subgroups within group 1, groups 1A and 1B (Schwartz et al. 2015). In addition to allelic variation in core genes, the majority of T4 $X$. perforans

TABLE 1. Xanthomonas perforans strains used in this study and their genotypes

\begin{tabular}{|c|c|c|c|c|c|c|c|c|c|}
\hline Strain & Source & Year & Host $^{\mathrm{a}}$ & Tomato race & $a v r X v 3^{\mathrm{b}}$ & avrBsT & xopJ4 & xop $Q$ allele & gapA allelec \\
\hline \multicolumn{10}{|c|}{$X$. perforans } \\
\hline Xp894 & Florida & 1991 & $\mathrm{~T}$ & $\mathrm{~T} 3$ & + & - & + & 1 & 1 \\
\hline Xp909 & Florida & & $\mathrm{T}$ & $\mathrm{T} 3$ & + & - & + & 1 & 1 \\
\hline Xp1183 & Florida & & $\mathrm{T}$ & $\mathrm{T} 3$ & + & - & + & 1 & 1 \\
\hline Xp1118 & Florida & 1992 & $\mathrm{~T}$ & $\mathrm{~T} 3$ & + & - & + & 1 & 1 \\
\hline Xp1144 & Florida & & $\mathrm{T}$ & $\mathrm{T} 3$ & + & - & + & 1 & 1 \\
\hline Xp1126 & Florida & & $\mathrm{T}$ & $\mathrm{T} 3$ & + & - & + & 1 & 1 \\
\hline Xp1221 & Florida & 1993 & $\mathrm{~T}$ & $\mathrm{~T} 3$ & + & - & + & 1 & 1 \\
\hline Xp1224 & Florida & & $\mathrm{T}$ & $\mathrm{T} 3$ & + & - & + & 1 & 1 \\
\hline Xp1241 & Florida & & $\mathrm{T}$ & $\mathrm{T} 3$ & + & - & + & 1 & 1 \\
\hline Xp1247 & Florida & & $\mathrm{T}$ & $\mathrm{T} 3$ & + & - & + & 1 & 1 \\
\hline Xp1262 & Florida & & $\mathrm{T}$ & $\mathrm{T} 3$ & + & - & + & 1 & 1 \\
\hline Xp1268 & Florida & & $\mathrm{T}$ & $\mathrm{T} 3$ & + & - & + & 1 & 1.2 \\
\hline Xp1275 & Florida & & $\mathrm{T}$ & $\mathrm{T} 3$ & + & - & + & 1 & 1.2 \\
\hline Xp1508 & Florida & & $\mathrm{T}$ & $\mathrm{T} 3$ & + & - & + & 1 & 1 \\
\hline Xp1345 & Mexico & & $\mathrm{T}$ & $\mathrm{T} 3$ & + & - & + & 1 & 1 \\
\hline Xp1485 & Mexico & & $\mathrm{T}$ & $\mathrm{T} 3$ & + & - & + & 1 & 1 \\
\hline Xp1550 & Florida & 1994 & $\mathrm{~T}$ & $\mathrm{~T} 3$ & + & - & + & 1 & 1.2 \\
\hline Xp1564 & Florida & & $\mathrm{T}$ & $\mathrm{T} 3$ & + & - & + & 1 & 1.2 \\
\hline Xp1574 & Florida & & $\mathrm{T}$ & $\mathrm{T} 3$ & + & - & + & 1 & 1 \\
\hline Xp1757 & Mexico & & $\mathrm{T}$ & $\mathrm{T} 3$ & + & - & + & 1 & 1 \\
\hline Xp1775 & NA & 1995 & $\mathrm{~T}$ & $\mathrm{~T} 3$ & + & - & + & 1 & 1 \\
\hline Xp1797 & Florida & & $\mathrm{T}$ & $\mathrm{T} 3$ & + & - & + & 1 & 1 \\
\hline Xp1805 & Florida & & $\mathrm{T}$ & $\mathrm{T} 3$ & + & - & + & 1 & 1 \\
\hline Xp1835 & Florida & 1996 & $\mathrm{~T}$ & $\mathrm{~T} 3$ & + & - & + & 1 & 1 \\
\hline Xp1856 & Florida & & $\mathrm{T}$ & $\mathrm{T} 3$ & + & - & + & 1 & 1 \\
\hline Xp1861 & Alabama & & $\mathrm{T}$ & $\mathrm{T} 3$ & + & - & + & 1 & 1 \\
\hline Xp1911 & Florida & 1997 & $\mathrm{~T}$ & $\mathrm{~T} 3$ & + & - & + & 1 & 1 \\
\hline Xp1912 & Florida & & $\mathrm{T}$ & $\mathrm{T} 3$ & + & - & + & 1 & 1 \\
\hline Xp1913 & Florida & & $\mathrm{T}$ & $\mathrm{T} 3$ & + & - & + & 1 & 3 \\
\hline Xp1920 & Florida & 1998 & $\mathrm{~T}$ & $\mathrm{~T} 3$ & + & - & + & 1 & 1 \\
\hline Scott-1 & Florida & & $\mathrm{T}$ & $\mathrm{T} 4$ & $\varnothing$ & + & + & 1 & 1 \\
\hline Xp1-5 & Florida & 2006 & $\mathrm{~T}$ & $\mathrm{~T} 3$ & + & + & + & 1 & 1 \\
\hline Xp1-6 & Florida & & $\mathrm{T}$ & $\mathrm{T} 3$ & + & + & + & 1 & 1 \\
\hline Xp1-13 & Florida & & $\mathrm{T}$ & $\mathrm{T} 3$ & + & - & + & 1 & 1 \\
\hline Xp3-8 & Florida & & $\mathrm{T}$ & $\mathrm{T} 3$ & + & + & + & 1 & 1 \\
\hline Xp3-12 & Florida & & $\mathrm{T}$ & $\mathrm{T} 3$ & + & + & + & 1 & 1 \\
\hline
\end{tabular}

a $\mathrm{T}=$ tomato; $\mathrm{P}=$ pepper.

b $\varnothing$, insertion sequence, could not be PCR amplified; $\partial$, potential pseudogene; ES, early stop codon detected in the sequence.

c The gapA allele 1 differed from allele 1.2 by only one nucleotide and is within the same genetic group as allele 1 .

d Sequence information of all T4 strains collected in 2006, 2010, and 2012 were previously published by Timilsina et al. 2015 and Schwartz et al. 2015.

e Housekeeping gene sequences of $X$. vesicatoria strains were published by Timilsina et al. 2015. 
strains collected in 2006 and 2012 contained avrBsT. The $X$. perforans type strain 91-118 did not have avrBsT. This effector, when expressed in $X$. perforans and translocated into pepper mesophyll cells, elicits a HR, while when expressed in $X$. vesicatoria and translocated into tomato mesophyll cells, this effector protein suppresses defense responses and increases virulence (Kim et al. 2010). A group 2 T4 strain of $X$. perforans from bell pepper was isolated that lacked AvrBsT (Schwartz et al. 2015). When avrBsT was mutated in group 2 strains originally isolated from tomato, they also caused lesions in pepper. However, mutation of avrBsT in group 1A $X$. perforans strains did not confer pathogenicity in pepper, suggesting that host range of $X$. perforans strains is determined, in part, by genetic background (Schwartz et al. 2015). Both XopQ and AvrBsT appear to have a role in host range, because double deletion of these two effectors also allowed host expansion of $X$. perforans to Nicotiana benthamiana (Schwartz et al. 2015).

The long-term effectiveness of an $R$ gene within a breeding program is generally dependent on the presence and fitness value of the corresponding effector gene within a defined pathogen population. However, in the case of tomato in Florida, unforeseen changes in the pathogen population due to the introduction of exotic species, mutations in effector genes, and even recombination among Xanthomonas species have necessitated the re-evaluation of resistance breeding strategies. The future of resistance breeding in tomato may fail if we do not understand the drivers of past changes within the pathogen population. The genomic variation found in Florida $\mathrm{T} 4 X$. perforans strains raised questions regarding variation in T3 $X$. perforans before and during the race shift. Is the avrBsT gene exclusive to T4 strains, indicating that it was acquired simultaneous to the loss of AvrXv3? Did recombination with $X$. euvesicatoria occur at the same time as loss of AvrXv3 or as gain of AvrBsT? In previous studies, only T4 strains had been genotyped (Schwartz et al. 2015; Timilsina et al. 2015). We hypothesized that the loss of AvrXv3, gain of AvrBsT, and recombination with $X$. euvesicatoria were related events, such that AvrBsT is exclusive to T4 recombinant strains. To test this hypothesis, we genotyped T3 strains from the 2006 and earlier surveys and compared them with T4 strains collected in 2006, 2010, and 2012. We sequenced the housekeeping gene gapA and the effector $x o p Q$, as indicators of the recombination event with $X$. euvesicatoria, to determine the timing of recombination relative to the race shift. We examined sequences of $a v r X v 3$ to determine the genetic basis of the race shift, and we sequenced $a v r B s T$ and xopJ4 to determine their stability as potential targets for resistance breeding against $X$. perforans.

\section{MATERIALS AND METHODS}

Bacterial strains collection and pathogenicity testing. Xanthomonas perforans strains used in this study were isolated over a period of 20 years from symptomatic plants (Table 1). In Florida, T3 and T4 strains of $X$. perforans were first identified in 1991 and 1998, respectively. Representative strains from each year between 1991-1998 and T3 strains from 2006 were selected for study. Additional T3 strains from Mexico and Alabama were also included for comparison.

Tomato and pepper differentials were inoculated to confirm pathogenicity and race (Stall et al. 2009). To determine race, bacterial

TABLE 1. (continued from preceding page)

\begin{tabular}{|c|c|c|c|c|c|c|c|c|c|}
\hline Strain & Source & Year & $\operatorname{Host}^{\mathrm{a}}$ & Tomato race & $a v r X v 3^{\mathrm{b}}$ & $a v r B s T$ & xopJ4 & $x o p Q$ allele & gapA allele \\
\hline Xp3-16 & Florida & & $\mathrm{T}$ & $\mathrm{T} 3$ & + & + & + & 1 & 1 \\
\hline Xp5-8 & Florida & & $\mathrm{T}$ & $\mathrm{T} 3$ & + & - & + & 1 & 1 \\
\hline Хp5-9 & Florida & & $\mathrm{T}$ & $\mathrm{T} 3$ & + & - & + & 1 & 1 \\
\hline Xp5-14 & Florida & & $\mathrm{T}$ & $\mathrm{T} 3$ & + & + & + & 1 & 1 \\
\hline Xp5-15 & Florida & & $\mathrm{T}$ & T3 & + & + & + & 1 & 1 \\
\hline Xp6-19 & Florida & & $\mathrm{T}$ & T3 & + & + & + & 1 & 1 \\
\hline Xp10-20 & Florida & & $\mathrm{T}$ & $\mathrm{T} 3$ & + & + & + & 1 & 1 \\
\hline Xp20-5 & Florida & & $\mathrm{T}$ & T3 & + & + & + & 1 & 1 \\
\hline Xp20-7 & Florida & & $\mathrm{T}$ & $\mathrm{T} 3$ & + & + & + & 1 & 1 \\
\hline Xp3-15 & Florida & & $\mathrm{T}$ & $\mathrm{T} 4^{\mathrm{d}}$ & $\varnothing$ & + & + & 2 & 2 \\
\hline Xp4-20 & Florida & & $\mathrm{T}$ & $\mathrm{T} 4$ & $\partial$ & + & + & 1 & 1 \\
\hline Xp5-6 & Florida & & $\mathrm{T}$ & $\mathrm{T} 4$ & $\partial$ & - & + & 1 & 1 \\
\hline Xp7-12 & Florida & & $\mathrm{T}$ & $\mathrm{T} 4$ & $\varnothing$ & + & + & 2 & 2 \\
\hline Xp8-16 & Florida & & $\mathrm{T}$ & $\mathrm{T} 4$ & $\varnothing$ & + & + & 2 & 2 \\
\hline Xp9-5 & Florida & & $\mathrm{T}$ & $\mathrm{T} 4$ & $\varnothing$ & + & + & 2 & 2 \\
\hline Xp10-13 & Florida & & $\mathrm{T}$ & $\mathrm{T} 4$ & $\varnothing$ & + & + & 2 & 2 \\
\hline Xp11-2 & Florida & & $\mathrm{T}$ & $\mathrm{T} 4$ & - & + & + & 1 & 1 \\
\hline Xp15-11 & Florida & & $\mathrm{T}$ & $\mathrm{T} 4$ & $\varnothing$ & + & + & 1 & 1 \\
\hline Xp17-12 & Florida & & $\mathrm{T}$ & $\mathrm{T} 4$ & - & - & + & 1 & 1 \\
\hline Xp18-15 & Florida & & $\mathrm{T}$ & $\mathrm{T} 4$ & - & + & + & 1 & 1 \\
\hline Xp2010 & Florida & 2010 & $\mathrm{P}$ & $\mathrm{T} 4$ & $\varnothing$ & - & - & 2 & 2 \\
\hline GEV839 & Florida & 2012 & $\mathrm{~T}$ & $\mathrm{~T} 4$ & $\varnothing$ & + & + & 2 & 2 \\
\hline GEV872 & Florida & & $\mathrm{T}$ & $\mathrm{T} 4$ & ES & + & + & 1 & 1 \\
\hline GEV893 & Florida & & $\mathrm{T}$ & $\mathrm{T} 4$ & ES & + & + & 1 & 1 \\
\hline GEV904 & Florida & & $\mathrm{T}$ & $\mathrm{T} 4$ & ES & + & + & 1 & 1 \\
\hline GEV909 & Florida & & $\mathrm{T}$ & $\mathrm{T} 4$ & ES & + & + & 1 & 1 \\
\hline GEV915 & Florida & & $\mathrm{T}$ & $\mathrm{T} 4$ & ES & + & + & 1 & 1 \\
\hline GEV917 & Florida & & $\mathrm{T}$ & $\mathrm{T} 4$ & ES & + & + & 1 & 1 \\
\hline GEV936 & Florida & & $\mathrm{T}$ & $\mathrm{T} 4$ & ES & + & + & 1 & 1 \\
\hline GEV940 & Florida & & $\mathrm{T}$ & $\mathrm{T} 4$ & ES & + & + & 1 & 1 \\
\hline GEV968 & Florida & & $\mathrm{T}$ & $\mathrm{T} 4$ & ES & + & + & 1 & 1 \\
\hline GEV993 & Florida & & $\mathrm{T}$ & $\mathrm{T} 4$ & ES & + & + & 1 & 1 \\
\hline GEV1001 & Florida & & $\mathrm{T}$ & $\mathrm{T} 4$ & $\varnothing$ & + & + & 2 & 2 \\
\hline GEV1026 & Florida & & $\mathrm{T}$ & $\mathrm{T} 4$ & ES & + & + & 1 & 1 \\
\hline GEV1044 & Florida & & $\mathrm{T}$ & $\mathrm{T} 4$ & $\varnothing$ & + & + & 2 & 2 \\
\hline GEV1054 & Florida & & $\mathrm{T}$ & $\mathrm{T} 4$ & $\varnothing$ & + & + & 2 & 2 \\
\hline GEV1063 & Florida & & $\mathrm{T}$ & $\mathrm{T} 4$ & $\varnothing$ & + & + & 2 & 2 \\
\hline \multicolumn{10}{|l|}{$X$. vesicatoria $^{\mathrm{e}}$} \\
\hline ETH17 & Ethiopia & 2011 & $\mathrm{~T}$ & $\mathrm{~T} 2$ & - & + & - & - & 4 \\
\hline Xv144 & Argentina & NA & $\mathrm{T}$ & $\mathrm{T} 2$ & - & + & - & - & 4 \\
\hline
\end{tabular}


suspensions of approximately $5 \times 10^{8} \mathrm{CFU} / \mathrm{ml}(0.3 \mathrm{~A}$ at $600 \mathrm{~nm})$ were infiltrated into tomato genotypes that included Hawaii 7998 with the $r x v$ resistance gene, FL216 with the $X v 3$ resistance gene, a tomato genotype carrying the RXopJ4 resistance locus from Solanum pinnellii LA716, and the susceptible cultivar Bonnie Best. Similarly, bacterial suspensions were infiltrated into four pepper genotypes, 'Early Calwonder' (ECW), ECW-10R, ECW-20R, and ECW-30R (Bouzar et al. 1994). X. euvesicatoria 85-10 and X. perforans 91-118 were used as control strains.

Gene sequencing. Bacterial DNA was extracted, using a selective precipitation method with $\mathrm{CTAB}-\mathrm{NaCl}$ extraction protocol (Ausubel et al. 1994). Previous studies using multilocus sequence analysis of six housekeeping genes showed different allelic forms of gapA and $g y r B$ that differentiated $X$. perforans group 1 from group 2 (Timilsina et al. 2015). To assign $X$. perforans strains used in this study to a group, we sequenced a portion of gapA. To examine allelic variation in effectors, partial sequences of $a v r X v 3$ and $x o p J 4$ ( $a v r X v 4)$, the effector genes responsible for determining tomato races in $X$. perforans, and $x o p Q$ were sequenced. We tested for the presence of $a v r B s T$ in T3 $X$. perforans strains, using internal and flanking primers. When found, the complete gene was amplified and sequenced. For sequence comparison, avrBsT from two X. vesicatoria strains, Xv144 and ETH17, isolated from Argentina and Ethiopia, respectively, was sequenced. Sanger sequencing was conducted at the Interdisciplinary Center for Biotechnology Research at the University of Florida. The target genes sequenced in this study are listed in Table 2 along with their respective primers.

Sequence analysis. Housekeeping and effector genes sequenced were compared with other reference Xanthomonas spp., including $X$. euvesicatoria, X. gardneri, X. vesicatoria, and X. perforans sequences available from the Plant Associated and Environmental Microbes Database (PAMDB) and the National Center for Biotechnology Information (NCBI). Sequence variation in the effector genes was screened comparing nucleotide polymorphisms using Basic Local Alignment Search Tool (BLAST) (Altschul et al. 1990). Allele designations were assigned manually based on sequence similarity. All sequences were aligned using the Muscle tool in MEGA software ver. 6 (Tamura et al. 2013). Sequences for the gapA housekeeping gene were used to construct a maximum likelihood phylogenetic tree using general time reversible model with gamma distributed invariant sites in MEGA software ver. 6 (Tamura et al. 2013). Model selection for phylogenetic analysis was determined using Akaike information criterion (Burnham and Anderson 2004).

Sequence submission. The genes sequenced for this study were submitted to the NCBI database. The accession numbers are KU759430 to KU759471 for partial gene sequences of gapA, KU759370 to KU759372 for complete coding regions of avrBsT, KU759373 to KU759401 for partial sequence of $a v r X v 3$, KU759402

TABLE 2. List of primers used in this study

\begin{tabular}{|c|c|c|c|}
\hline Gene $^{\mathrm{a}}$ & Direction & Sequence & Reference \\
\hline \multirow[t]{2}{*}{$x o p Q^{*}$} & Forward & AAGCTCGGCATGGTGGTCAT & \multirow[t]{2}{*}{ This study } \\
\hline & Reverse & AGCAGGGTCAGCGGATCGTA & \\
\hline \multirow[t]{2}{*}{$\operatorname{avrBs} T^{\wedge}$} & Forward & TTGGAACAACTCCTGGCG & \multirow[t]{2}{*}{ This study } \\
\hline & Reverse & ATGCACCGCACTATGCACAT & \\
\hline \multirow[t]{2}{*}{$\operatorname{avrBs} T^{*}$} & Forward & TGTTGGTAATTGAGCCAGCACTTG & \multirow[t]{2}{*}{ This study } \\
\hline & Reverse & AGTTGGATGACCGCCATGTCTC & \\
\hline \multirow[t]{2}{*}{$\operatorname{avrXv3*}$} & Forward & AGCAACTGTCTGCCAGCCAGAACC & \multirow[t]{2}{*}{ This study } \\
\hline & Reverse & TGAGCGAGAGCTACTATCGCCTCC & \\
\hline \multirow[t]{2}{*}{ xорJ4* } & Forward & ACTCGCCAAATTGTCATGC & \multirow[t]{2}{*}{ This study } \\
\hline & Reverse & TACGACCTTTTCAGGGTTGG & \\
\hline \multirow[t]{2}{*}{ gapA* } & Forward & GGCAATCAAGGTTGGYATCAACG & \multirow{2}{*}{$\begin{array}{l}\text { Almeida } \\
\text { et al. } 2010\end{array}$} \\
\hline & Reverse & ATCTCCAGGCACTTGTTSGARTAG & \\
\hline
\end{tabular}

\footnotetext{
a An asterisk (*) indicates internal primers for genes $x o p Q, a v r B s T$, avrXv3, xopJ4 and gapA and a carat $(\wedge)$ indicates a complete coding region for the avrBsT gene.
}

to KU759429 for partial sequence of xopJ4, and KU759472 to KU759498 for partial sequence of $x o p Q$. The reference gene sequences used during this study are available on the NCBI and PAMDB databases.

\section{RESULTS}

Pathogenicity and race determination. Strains previously assigned to tomato race 3 were confirmed as T3. These strains were pathogenic on tomato differentials 'Bonnie Best' and Hawaii 7998 but elicited a HR on the tomato cultivars carrying the $X v 3$ resistance gene and the RXopJ4 resistance gene (Table 1). One $X$. perforans strain isolated in 1998, Scott-1, was confirmed as T4. It did not elicit a HR on FL216, which carries the $X v 3$ gene. PCR amplification of the $a v r X v 3$ and $x o p J 4$ effector genes produced results consistent with the assigned tomato race.

Grouping of T3 strains by gapA sequence. The housekeeping gene gapA differentiates the two genetic groups of T4 $X$. perforans strains (Timilsina et al. 2015). Group 2 strains of T4 $X$. perforans have a gapA sequence identical to the $X$. euvesicatoria gapA gene, which differs by 4 or 5 nucleotides from the group 1 alleles. Sequencing of gapA in T3 $X$. perforans strains isolated between 1991 and 2006 revealed three different alleles (Fig. 1; Supplementary Fig. S1). Sequence comparisons showed a single nucleotide difference in gapA between strain 91-118 and strains Xp1268, Xp1275, Xp1550, and Xp1564, isolated in 1993 or 1994 (Table 1, allele 1.2). Strain Xp1913 differed from strain 91-118 by 19 nucleotides for gapA. This allele was most similar to a nonpathogenic strain, ETH12, isolated from tomato in Ethiopia (Kebede et al. 2014). All of the T3 strains collected in 2006 were identical to each other and to strain 91-118 for gapA. None of the T3 strains contained a gapA allele identical to the group 2 recombinant $\mathrm{T} 4 X$. perforans strains.

Effector gene sequences. Four effector genes, $a v r X v 3$, xopJ4, xop $Q$ and $a v r B s t$, were sequenced for the study. Effector gene sequences $a v r X v 3$ and $x o p J 4$ were found to be identical in all examined T3 X. perforans strains. Whole genome sequences of T4 $X$. perforans strains were examined for the presence and allelic diversity of the $a v r X v 3$ gene. Three different mutations were observed in $a v r X v 3$ (Supplementary Fig. S2). In group 2 strains, there was a contig break in $a v r X v 3$, with remnants of an insertion sequence. Primers specific to $a v r X v 3$ were not able to amplify the gene, and inoculations in tomato differentials indicated that AvrXv3 was nonfunctional in these strains. Within group 1 strains, the two subgroups that were previously defined by whole-genome sequencing (Schwartz et al. 2015), showed different forms of mutations in $a v r X v 3$. In group 1A, an early stop codon was detected, due to a point mutation. In group $1 \mathrm{~B}, a v r X v 3$ was either completely absent or truncated, rendering AvrXv3 nonfunctional in both cases. In contrast, xopJ4 had identical sequence in all T3 and T4 strains of $X$. perforans.

Like gapA, T4 $X$. perforans strains have two allelic forms of XopQ consistent with the two groups (Schwartz et al. 2015). The $x o p Q$ sequence of group 1 strains is identical to type strain 91-118, but group 2 strains have a $x o p Q$ sequence identical to $X$. euvesicatoria. The difference between these alleles of XopQ is 10 nucleotides, or 6 amino acids (Supplementary Fig. S3). For all T3 X. perforans strains examined, $x o p Q$ sequences were identical to strain 91-118 and group $1 \mathrm{~T} 4 \mathrm{X}$. perforans strains, consistent with the gapA results.

Presence of AvrBsT in T3 $X$. perforans. Primers were designed to amplify the entire type III secreted effector gene $a v r B s T$ along with approximately $0.5-\mathrm{kb}$ flanking regions on either side of the gene. These primers identified the presence of $a v r B s T$ gene in T3 strains of $X$. perforans isolated in 2006 but not prior to 2006 (Table 1). Although primers were designed for polymesae chain reaction (PCR) amplification of avrBsT, two different band sizes were observed during gel electrophoresis (Supplementary Fig. S4). The expected band size, that of the functional avrBsT gene in T4 $X$. perforans strains, was approximately $2 \mathrm{~kb}$. Sequencing of the 
2-kb band amplified from T3 $X$. perforans strains showed an intact avrBsT gene that was identical to that in T4 X. perforans strains. A smaller, approximately 1.2-kb band was observed in strain Xp1861 isolated in 1996 from Alabama and in strain Xp1-13 isolated in
2006 from Florida. These PCR products were sequenced and were determined to have no homology to $\operatorname{avrBs} T$, but a fragment of transposon sequence was found. The primers for avrBsT were designed to anneal the flanking sequence of the gene but were also

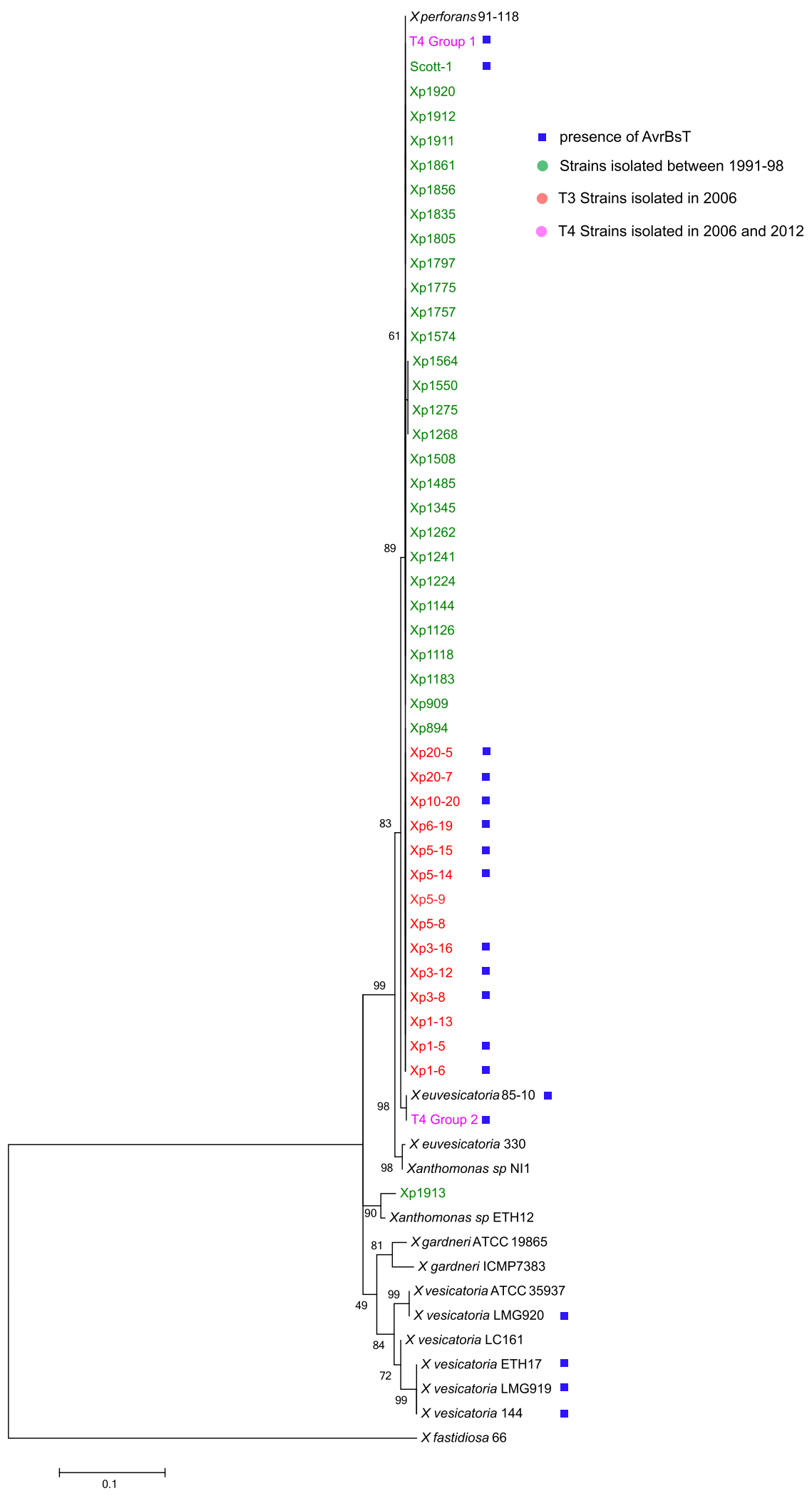

Fig. 1. Maximum likelihood phylogenetic analysis of Xanthomonas perforans strains using gapA gene sequence. Strains are color-coded based on the years they were isolated. T4 group 1 and T4 group 2 represent the gapA sequences for these respective group of strains collected in 2006 and 2012 . Reference strains of X. euvesicatoria, X. gardneri, X. perforans, and X. vesicatoria were downloaded from the Plant Associated and Environmental Microbes Database and the National Center for Biotechnology Information database. Values on the branches indicate bootstrap values for each branch, expressed as percentages. The scale bar indicates the number of substitutions per site. 
found to be identical to the putative transposon region. Primers internal to the coding region of the $a v r B s T$ gene were used to further confirm the presence or absence of $a v r B s T$ in all strains. The $X$. perforans strains collected from 1991 to 1998 lacked avrBsT, while all but two of the T3 strains collected in 2006 contained the gene. The $a v r B s T$ gene sequences from both T3 and T4 strains of $X$. perforans were identical to the avrBs $T$ gene from $X$. vesicatoria Bv5-4a (GQ266402.1) but varied from the $a v r B s T$ gene from $X$. euvesicatoria $75-3$ by 2 nucleotides (AF156163.1). We found the $X$. perforans-type avrBsT allele in other $X$. vesicatoria strains (Fig. 2). An identical avrBsT allele is also present in the cassava pathogen X. axonopodis pv. manihotis CIO151 (AKDA01000004).

\section{DISCUSSION}

Bacterial spot disease of tomato and pepper is caused by four different Xanthomonas species, but tomato in Florida is currently affected only by $X$. perforans and, in recent years, only tomato race 4 strains of $X$. perforans have been found (Schwartz et al. 2015). Prior to 1991, only tomato race 1 X. euvesicatoria was isolated from bacterial spot-affected tomato in Florida. The population shift from

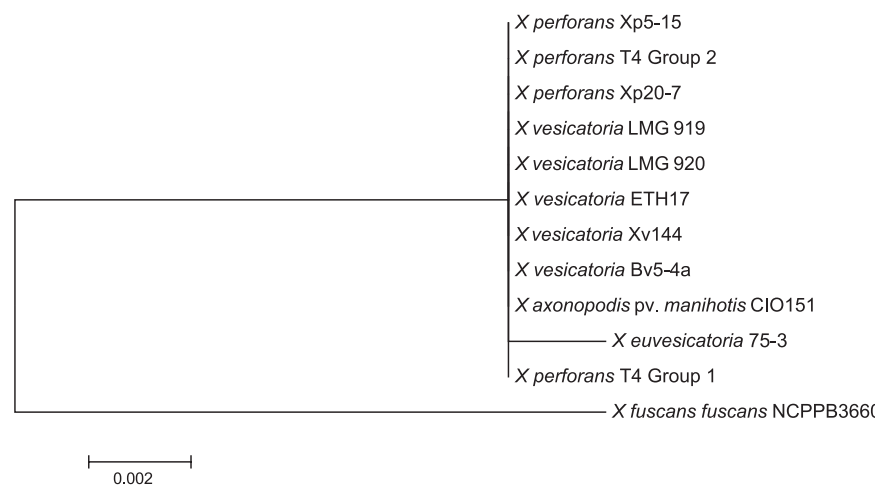

Fig. 2. Maximum likelihood phylogenetic tree of avrBsT, showing sequence identity between alleles in Xanthomonas vesicatoria and X. perforans strains. Additionally, the avrBsT sequence from $X$. axonopodis pv. manihotis was identical to the avrBsT in bacterial spot-causing Xanthomonas strains.
$\mathrm{T} 1 X$. euvesicatoria to T3 $X$. perforans was attributed to bacteriocin activity of T3 X. perforans (Hert et al. 2005). The shift from T3 to T4 started in 1998, when the first T4 strain was found (strain Scott-1) and was complete by 2012 (Fig. 3). The reason for the population shift from T3 to T4 $X$. perforans remains unknown, as no known sources of resistance toward $X$. perforans are commercially available. Whole-genome sequence analysis of $X$. perforans identified a substantial variation in the effector profiles among T4 strains collected in 2006 and 2012 and a recombination event affecting gapA and xopQ, among other genes (Schwartz et al. 2015; Timilsina et al. 2015). The most notable change in effector profiles, in comparison with the T3 strain 91-118, was the presence of the avrBsT gene in most of the T4 X. perforans strains. The avrBsT effector is universally recognized by most varieties of pepper. Kim et al. (2010) demonstrated that $X$. vesicatoria Bv5-4a with avrBsT exhibited higher in planta titers postinoculation on a susceptible tomato line, compared with strains lacking avrBsT. Therefore, $X$. perforans strains with avrBsT may have gained increased virulence and fitness on tomato. Only three strains of group 2 T4 X. perforans have been found without the gene for AvrBsT to date. X. perforans is usually only pathogenic on tomato, but an $X$. perforans strain was isolated from symptomatic pepper that lacked AvrBsT (Schwartz et al. 2015) (Fig. 3; Supplementary Table S1). To determine if changes were occurring in the Florida population prior to the race shift, we characterized T3 strains of $X$. perforans that were collected from 1991 to 2006 . We did not find recombinant gapA or $x o p Q$ genes in $\mathrm{T} 3 X$. perforans. In addition, all strains exhibited identical $a v r X v 3$ and $x o p J 4$ gene sequences. Given the apparent homogeneity of the T3 $X$. perforans population, we were surprised to find $a v r B s T$ in T3 strains isolated in 2006. Thus, our results show that AvrBsT was acquired before the race shift or during the race shift by both T3 and T4 $X$. perforans strains.

All T3 X. perforans strains isolated in 2006 had the same avrBsT allele as T4 $X$. perforans. Interestingly, this allele has two adjacent nucleotides that are different from the avrBsT sequence in the $X$. euvesicatoria type strain 85-10. The two sites result in substitutions of two adjacent amino acids in the AvrBsT protein. The avrBsT gene from $X$. perforans was identical to the avrBs $T$ gene of $X$. vesicatoria LMG 919, isolated from Zimbabwe (GCA_001469445.1). Identical $a v r B s T$ sequence was detected in other $X$. vesicatoria strains

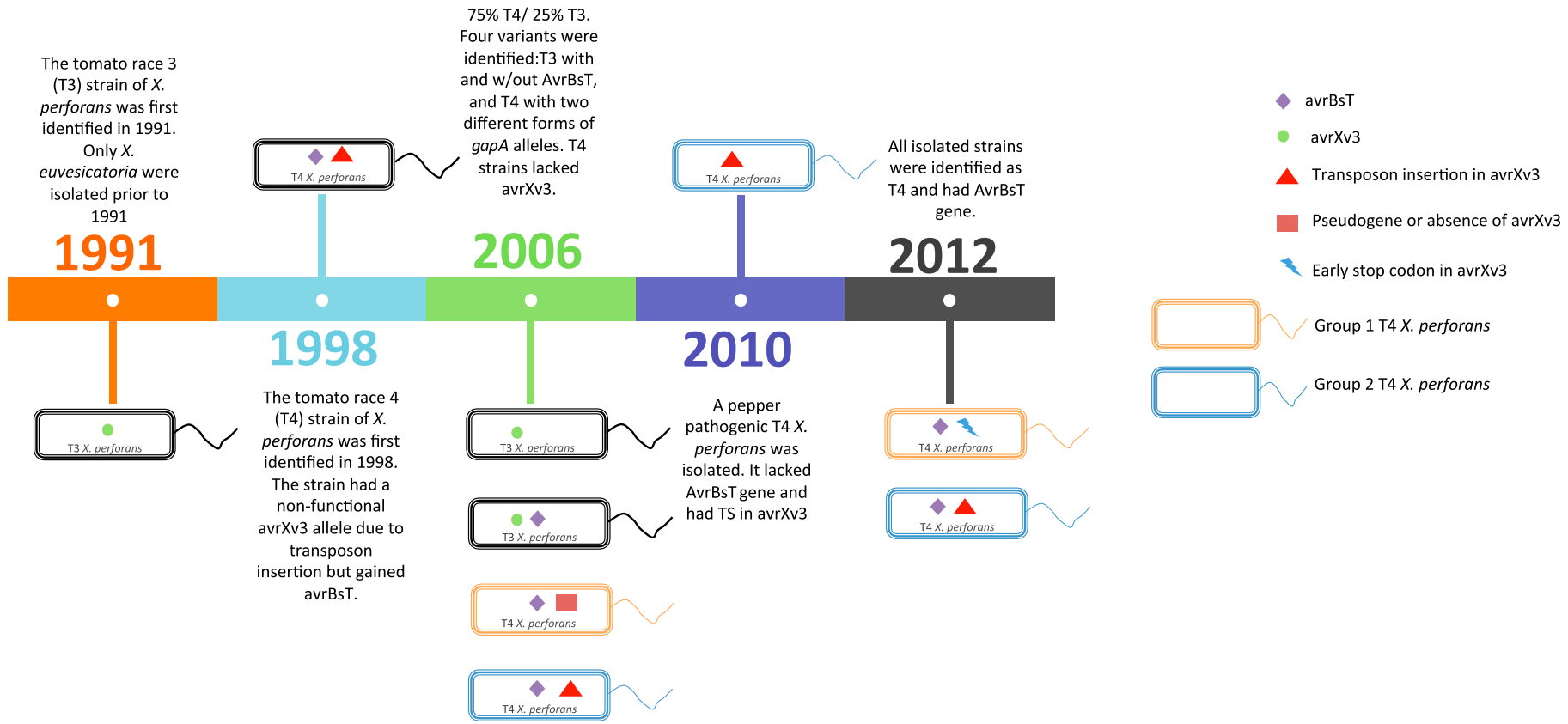

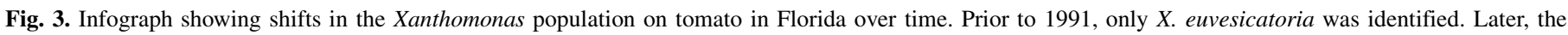

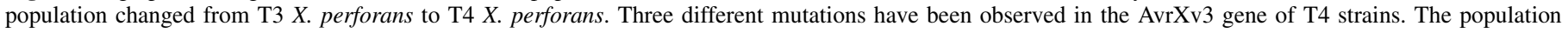
acquired AvrBsT, which was first observed in 1998, in most strains in 2006, and in all strains examined from 2012. 
isolated from Argentina and Ethiopia that were sequenced during this study. The effector is not universally present in $X$. vesicatoria, as the type strain of $X$. vesicatoria, ATCC 35937, appears to lack the $a v r B s T$ gene. $X$. vesicatoria is known to be resistant to bacteriocins produced by $X$. perforans and, given the sequence identity of $a v r B s T$ between these two species, avrBsT may have been acquired through horizontal gene transfer from strains of $X$. vesicatoria carrying avrBsT. This is a surprising find, because there are no reports of $X$. vesicatoria in Florida. However, the presence of multiple Xanthomonas species was associated with bacterial spot in Africa (Jibrin et al. 2015; Kebede et al. 2014; Timilsina et al. 2015). The presence of multiple Xanthomonas species within the same tomato-growing region increases the likelihood of genetic exchange between species. Further studies examining the global distribution of avrBsT in the Xanthomonas bacterial spot species could help to clarify the importance of this effector in Xanthomonas populations on tomato, determine whether there is selection for strains carrying $a v r B s T$, and identify the $a v r B s T$ donor to $X$. perforans.

We previously found genetic exchange among bacterial species affecting housekeeping genes and the $x o p Q$ effector (Schwartz et al. 2015; Timilsina et al. 2015). Whole-genome sequencing confirmed that there are at least two genetic groups of T4 X. perforans, with group 2 identified as recombinants with $X$. euvesicatoria. Within group 1, two subgroups were observed. Group 1A was identified exclusively in 2012. Group 1B is a more genetically diverse group that includes the type strain 91-118 but does not include any strains collected in 2012. The groups are defined based on core genome phylogeny, yet each group has distinct unique mutations in the $a v r X v 3$ gene resulting in a shift from T3 to T4. Group 1A had a point mutation resulting in an early stop codon, group $1 \mathrm{~B}$ either lacked the entire $a v r X v 3$ coding region or a section of the gene making it a likely pseudogene, and group 2 contained insertion sequences in $a v r X v 3$ (Fig. 3). The unique mutations within the genetically homogenous Groups $1 \mathrm{~A}$ and 2 suggest that the distinct mutations in $a v r X v 3$ occurred in a strain ancestral to each of these groups and any further variation in effector profiles occurred after the loss of AvrXv3.

We looked for evidence of recombination with $X$. euvesicatoria in T3 strains by sequencing the gapA and $x o p Q$ genes. We found no variation in $x o p Q$ within T3 strains. T3 strains had three gapA alleles, but none of them were the recombinant allele from $X$. euvesicatoria. The most common allele was identical to that of $X$. perforans type strain 91-118, while the second allele varied by only one nucleotide and was isolated in 1993 and 1994 only. The third allele found in strain Xp1913, isolated in 1996 in Alabama, exhibited a gapA gene sequence that differed by 19 nucleotides from the other sequenced $X$. perforans strains. This gapA sequence is closely related to an unknown Xanthomonas species isolated from Ethiopia and originally identified as $X$. euvesicatoria but found to be nonpathogenic on tomato (Kebede et al. 2014). Here, Xp1913 was identified as a T3 $X$. perforans by inoculation on differential tomato lines and based on sequence similarity of the $a v r X v 3$ and XopJ4 genes to other sequenced $X$. perforans strains.

The development of tomato cultivars with individual dominant $R$ genes to bacterial spot has been undermined by changes in bacterial spot species and their effectors. A long-term breeding program to introgress $X v 3$ into tomato genotypes began in 1991 after the displacement of T1 $X$. euvesicatoria by T3 X. perforans in Florida. In 1998, $X$. perforans overcame this resistance as a result of a mutation in $a v r X v 3$, prior to commercial deployment of $X v 3$. More concerning was that by $2006,75 \%$ of the Florida population contained mutations in avrXv3 without any apparent selection pressure. Similarly, in pepper, $B s 2$ was introgressed into commercial pepper genotypes in an effort to produce cultivars with durable resistance to the bacterial spot pathogen. Although pepper cultivars containing $B s 2$ provided high levels of resistance for a few years, bacterial spot began to develop on the cultivars resulting in significant disease. Gassmann et al. (2000) characterized Xanthomonas strains associated with these outbreaks and determined that point mutations occurred in $a v r B s 2$ that resulted in the protein not being recognized by Bs2 but still allowed AvrBs2 to function as a virulence factor in pepper. Although $B s 2$ has been transferred to tomato (Horvath et al. 2012), it is unlikely that this gene alone will provide durable resistance. Therefore identifying multiple $R$ genes that target Xanthomonas effectors will be required.

Breeding for resistance against pathogens depends on selecting appropriate effector gene targets. A single nucleotide variation in an effector may undermine the usefulness of the resistance gene. Thus, for breeding purposes, effectors that have conserved sequences within a diverse pathogen population would be preferred. One or more factors driving the race shift from T3 to T4 in the X. perforans population in Florida remains unknown. However, our data suggest that mutations in $a v r X v 3$ were associated with other simultaneous changes in the population that resulted in additional variation in effector profiles. Nevertheless, we confirmed that the xopJ4 gene is conserved in all $X$. perforans strains regardless of tomato race or genetic group and in strains collected over a period of 20 years. Effector XopJ4 is currently a stable effector in X. perforans. Likewise, the acquisition of the avrBsT gene in $X$. perforans makes this gene another potential target for resistance breeding. Preliminary field data indicate that AvrBsT is a virulence factor in $X$. perforans (P. Abrahamian J. B. Jones, and G. E. Vallad, unpublished data), and this effector is largely present in recent $X$. perforans collections. Additionally, corresponding host resistance has been studied against both XopJ4 and AvrBsT effectors. A resistance locus, RXopJ4, that recognizes xopJ4 was mapped (Sharlach et al. 2013) and identified in the wild tomato accession Solanum pennellii LA716. The locus is a 4.2-Mb segment conferring resistance to Xanthomonas strains carrying xopJ4 and the resistance gene was fine-mapped to a 190-kb region. Likewise, heat-shock protein $70 \mathrm{a}$ was recently reported to interact with the avrBsT effector to induce programmed cell death in pepper (Kim and Hwang 2015). An incompatible reaction in the presence of avrBsT gene was observed in S. lycopersicoides and its hybrid, S. lycopersicum (Wang 1992), as well as in most pepper cultivars (Potnis et al. 2011), although the resistance locus has not been identified. Additional studies are needed to identify the specific $R$ genes against xopJ4 and avrBsT. In conclusion, these genes could potentially be pyramided with the $B s 2$ resistance gene to develop cultivars with more durable resistance against $X$. perforans in Florida.

\section{ACKNOWLEDGMENTS}

We thank B. Vinatzer and three anonymous reviewers for their comments on the manuscript. This research was supported in part with funds from the United States Department of Agriculture National Institute of Food and Agriculture Specialty Crop Research Initiative program and the Florida Department of Agriculture and Consumer Services Specialty Crops block grant program.

\section{LITERATURE CITED}

Almeida, N. F., Yan, S., Cai, R., Clarke, C. R., Morris, C. E., Schaad, N. W., Schuenzel, E. L., Lacy, G. H., Sun, X., Jones, J. B., Castillo, J. A., Bull, C. T., Leman, S., Guttman, D. S., Setubal, J. C., and Vinatzer, B. A. 2010. PAMDB, a multilocus sequence typing and analysis database and website for plant-associated microbes. Phytopathology 100:208-215.

Altschul, S. F., Gish, W., Miller, W., Myers, E. W., and Lipman, D. J. 1990. Basic local alignment search tool. J. Mol. Biol. 215:403-410.

Astua-Monge, G., Minsavage, G. V., Stall, R. E., Vallejos, C. E., Davis, M. J., and Jones, J. B.. 2000. Xv4-avrXv4: A new gene-for-gene interaction identified between Xanthomonas campestris pv. vesicatoria race T3 and wild tomato relative Lycopersicon pennellii. Mol. Plant-Microbe Interact. 13:1346-1355.

Ausubel, F. M., Brent, R., Kingston, R. E., Moore, D. D., Seidman, J. G., Smith, J. A., and Struhl, K. 1994. Current Protocols in Molecular Biology. John Wiley and Sons, New York. 
Bouzar, H., Jones, J. B., Stall, R. E., Hodge, N. C., Minsavage, G. V., Benedict, A. A., and Alvarez, A. M. 1994. Physiological, chemical, serological, and pathogenic analyses of a worldwide collection of Xanthomonas campestris pv. vesicatoria strains. Phytopathology 84:663-671.

Burnham, K. P., and Anderson, D. R. 2004. Multimodel inference: Understanding AIC and BIC in model selection. Sociol. Methods Res. 33: 261-304.

Gassmann, W., Dahlbeck, D., Chesnokova, O., Minsavage, G. V., Jones, J. B., and Staskawicz, B. J. 2000. Molecular evolution of virulence in natural field strains of Xanthomonas campestris pv. vesicatoria. J. Bacteriol. 182:70537059.

Hert, A. P., Roberts, P. D., Momol, M. T., Minsavage, G. V., Tudor-Nelson, S. M., and Jones, J. B. 2005. Relative importance of bacteriocin-like genes in antagonism of Xanthomonas perforans tomato race 3 to Xanthomonas euvesicatoria tomato race 1 strains. Appl. Environ. Microbiol. 71:35813588.

Horvath, D. M., Stall, R. E., Jones, J. B., Pauly, M. H., Vallad, G. E., Dahlbeck, D., Staskawicz, B. J., and Scott, J. W. 2012. Transgenic resistance confers effective field level control of bacterial spot disease in tomato. PLoS One 7: e42036.

Huang, C.-H., Vallad, G. E., Zhang, S., Wen, A., Balogh, B., Figueiredo, J. F., Jones, J. B., Momol, T., and Olson, S. 2012. The effect of application frequency and reduced rates of acibenzolar- $S$-methyl on the field efficacy of induced resistance against bacterial spot of tomato. Plant Dis. 96:221-227.

Jibrin, M.O., Timilsina, S., Potnis, N., Minsavage, G. V., Shenge, K. C., Akpa, A. D., Alegbejo, M. D., Beed, F., Vallad, G. E., and Jones, J. B. 2015. First report of atypical Xanthomonas euvesicatoria strains causing bacterial spot of tomato in Nigeria. Plant Dis. 99:415.

Jones, J. B., Lacy, G. H., Bouzar, H., Stall, R. E., and Schaad, N. W. 2004. Reclassification of the xanthomonads associated with bacterial spot disease of tomato and pepper. Syst. Appl. Microbiol. 27:755-762.

Kebede, M., Timilsina, S., Ayalew, A., Admassu, B., Potnis, N., Minsavage, G. V., Goss, E. M., Hong, J. C., Strayer, A., Paret, M., Jones, J. B., and Vallad, G. E. 2014. Molecular characterization of Xanthomonas strains responsible for bacterial spot of tomato in Ethiopia. Eur. J. Plant Pathol. 140:677-688.

Kim, N. H., Choi, H. W., and Hwang, B. K. 2010. Xanthomonas campestris pv. vesicatoria effector avrBsT induces cell death in pepper, but suppresses defense responses in tomato. Mol. Plant Microbe Interact. 23:1069-1082.

Kim, N. H., and Hwang, B. K. 2015. Pepper heat shock protein 70a interacts with the type III effector AvrBsT and triggers plant cell death and immunity. Plant Physiol. 167:307-322.

McDonald, B. A., and Linde, C. 2002. Pathogen population genetics, evolutionary potential, and durable resistance. Annu. Rev. Phytopathol. 40:349-379.

Mhedbi-Hajri, N., Hajri, A., Boureau, T., Darrasse, A., Durand, K., Chrystelle, B., Saux, M. F., Manceau, C., Poussier, S., Pruvost, O., Lemaire, C., and Jacques, M. A. 2013. Evolutionary history of the plant pathogenic bacterium Xanthomonas axonopodis. PLoS One 8:e58474.

Nimchuk, X., Eulgem, T., Holt, B. F., III, and Dangi, J. L. 2003. Recognition and response in the plant immune system. Annu. Rev. Genet. 37:579-609.

Potnis, N., Krasileva, K., Chow, V., Almeida, N. F., Patil, P. B., Ryan, R. P., Sharlach, M., Behlau, F., Dow, J. M., Momol, M. T., White, F. F., Preston,
J. F., Vinatzer, B. A., Koebnik, R., Setubal, J. C., Norman, D. J., Staskawicz, B. J., and Jones, J. B. 2011. Comparative genomics reveals diversity among xanthomonads infecting tomato and pepper. BMC Genomics 12:146.

Potnis, N., Timilsina, S., Strayer, A., Shantharaj, D., Barak, J. D., Paret, M. L., Vallad, G. E., and Jones, J. B. 2015. Bacterial spot of tomato and pepper: Diverse Xanthomonas species with a wide variety of virulence factors posing a worldwide challenge. Mol. Plant Pathol. 16:907-920.

Schwartz, A. R., Potnis, N., Timilsina, S., Wilson, M., Patané, J., Martins, J., Jr., Minsavage, G. V., Dahlbeck, D., Akhunova, A., Almeida, N., Vallad, G. E., Barak, J. D., White, F. F., Miller, S. A., Ritchie, D., Goss, E. M., Bart, R. S., Setubal, J. C., Jones, J. B., and Staskawicz, B. J. 2015. Phylogenomics of Xanthomonas field strains infecting pepper and tomato reveals diversity in effector repertoires and indetifies determines of host specificity. Front. Microbiol. 6:535.

Scott, J. W., Jones, J. B., and Somodi, G. C. 1989. Inheritance of resistance in tomato to race T3 of the bacterial spot pathogen. J. Am. Soc. Hortic. Sci. 126:436-441.

Sharlach, M., Dahlbeck, D., Liu, L., Chiu, J., Jiménez-Gómez, J. M., Kimura, S., Koenig, D., Maloof, J. N., Sinha, N., Minsavage, G. V., Jones, J. B., Stall, R. E., and Staskawicz, B. J. 2013. Fine genetic mapping of RXopJ4, a bacterial spot disease resistance locus from Solanum pennellii LA716. Theor. Appl. Genet. 126:601-609.

Stall, R. E., Jones, J. B., and Minsavage, G. V. 2009. Durability of resistance in tomato and pepper to xanthomonads causing bacterial spot. Annu. Rev. Phytopathol. 47:265-284.

Swords, K. M., Dahlbeck, D., Kearney, B., Roy, M., and Staskawicz, B. J. 1996. Spontaneous and induced mutations in a single open reading frame alter both virulence and avirulence in Xanthomonas campestris pv. vesicatoria avrBs2. J. Bacteriol. 178:4661-4669.

Tai, T. H., Dahlbeck, D., Clark, E. T., Gajiwala, P., Pasion, R., Whalen, M. C., Stall, R. E., and Staskawicz, B. J. 1999. Expression of the Bs2 pepper gene confers resistance to bacterial spot disease in tomato. Proc. Natl. Acad. Sci. USA 96:14153-14158.

Tamura, K., Stecher, G., Peterson, D., Filipski, A., and Kumar, S. 2013. MEGA6: Molecular evolutionary genetics analysis version 6.0. Mol. Biol. Evol. 30:2725-2729.

Teper, D., Salomon, D., Sunitha, S., Kim, J. G., Mudgett, M. B., and Sessa, G. 2014. Xanthomonas euvesicatoria type III effector XopQ interacts with tomato and pepper 14-3-3 isoforms to suppress effector-triggered immunity. Plant J. 77:297-309.

Timilsina, S., Jibrin, M. O., Potnis, N., Minsavage, G. V., Kebede, M., Schwartz, A., Bart, R., Staskawicz, B. J., Boyer, C., Vallad, G. E., Pruvost, O., Jones, J. B., and Goss, E. M. 2015. Multilocus sequence analysis of xanthomonads causing bacterial spot of tomato and pepper plants reveals strains generated by recombination among species and recent global spread of Xanthomonas gardneri. Appl. Environ. Microbiol. 81:1520-1529.

Wang, J. F. 1992. A new race of Xcv on tomato and screening tomato genotypes for resistance to this new race. Resistance to Xanthomonas campestris pv. vesicatoria in tomato. Ph.D. dissertation. University of Florida, Gainesville, FL.

White, F. F., Potnis, N., Jones, J. B., and Koebnik, R. 2009. The type III effectors of Xanthomonas. Mol. Plant Pathol. 10:749-766.

This article was modified on 19 Sep 2019. 


\section{ERRATUM / Volume 106, Number 10, 2016 / PHYTO-03-16-0119-FI}

In the article "Analysis of Sequenced Genomes of Xanthomonas perforans Identifies Candidate Targets for Resistance Breeding in Tomato" by S. Timilsina, P. Abrahamian, N. Potnis, G. V. Minsavage, F. F. White, B. J. Staskawicz, J. B. Jones, G. E. Vallad, and E. M. Goss, XopJ4 for strain Xp2010 was changed from + to - in Table 1 and X. euvesicatoria 85-10 was changed to X. euvesicatoria 75-3 in the last paragraph of the Results section and in Figure 2. The correct strain is shown below in revised Figure 2.

\section{Revised Figure 2}

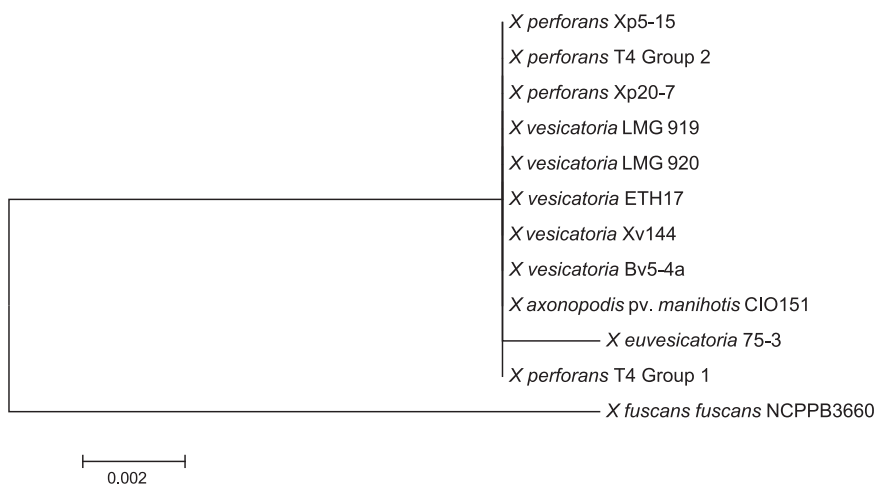

Fig. 2. Maximum likelihood phylogenetic tree of avrBsT, showing sequence identity between alleles in Xanthomonas vesicatoria and $x$. perforans strains. Additionally, the avrBs $T$ sequence from $X$. axonopodis pv. manihotis was identical to the avrBsT in bacterial spot-causing Xanthomonas strains.

\section{Previously Published Version}

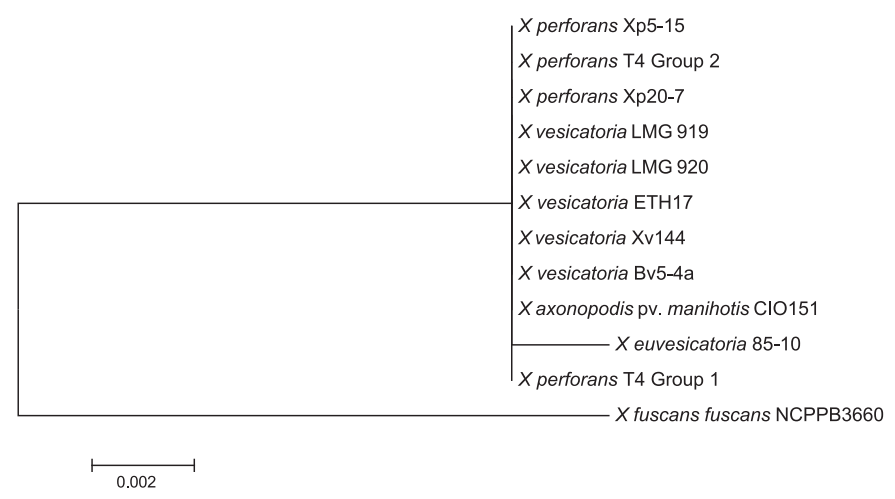

Fig. 2. Maximum likelihood phylogenetic tree of avrBsT, showing sequence identity between alleles in Xanthomonas vesicatoria and $x$. perforans strains. Additionally, the avrBsT sequence from $X$. axonopodis pv. manihotis was identical to the avrBsT in bacterial spot-causing Xanthomonas strains. 